\title{
Design and Developing a Linear Tables by Applying Piezoelectric Inchworm Moves
}

\author{
Alireza Zarreh ${ }^{1}$, Mohamad Saied Sepasi ${ }^{2}$, Maziar Sadeghi ${ }^{3}$ \\ Department of Manufacturing, School of Mechanical Engineering, College of Engineering, University of Tehran, \\ Tehran, Iran \\ alireza_zarreh@yahoo.ca
}

\begin{abstract}
:
This paper designed and developed a nano-positioning stage with linear movement as an essential part of the development of a micro-lathe. This stage uses an inchworm movement that drives with three high resolution piezoelectric that provides an unlimited movement range with high resolution in the nano range. This paper firstly discusses the table movement's mechanism and design. Then, with unitizing finite element analysis and mathematical modeling, the outputs such as resolution, velocity, and power are analyzed according to input parameters such as voltage and frequency. Results show that the accuracy and rigidity of this table in comparison with other nano-positioning tables prototype is higher.
\end{abstract}

\footnotetext{
${ }^{1}$ M.Sc. of Mechanical Engineering, Manufacturing

${ }^{2}$ Assistant Professor of Mechanical Engineering

${ }^{3}$ M.Sc. of Mechanical Engineering, Manufacturing
} 


\title{
طراحى و توسعه ميز خطى با استفاده از حركت حلزونى ييزوالكتريكها
}

\author{
على رضا ذرّه'، محمد سعيد سياسى ‘همازياز صادقى \\ دانشكاه تهر ان، برديس دانشكده هاى فنى، دانشكده مكانيك، گروه ساخت و توليد \\ alireza_zarreh@yahoo.ca
}

\section{جكيده}

ميز با تفكيك يذيرى در حد نانومتر به منظور استفاده در ميكروتراش طراحى شده است. اين ميز با استفاده

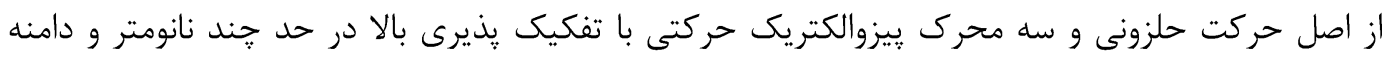

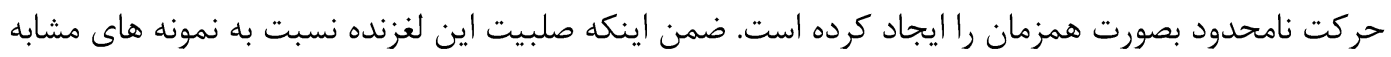

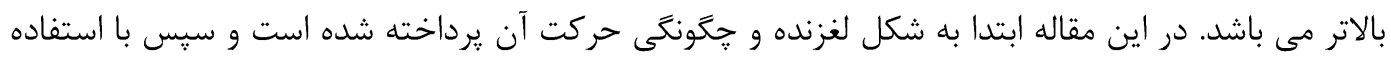

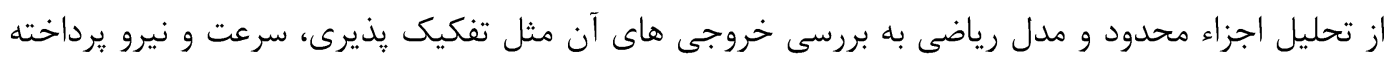

اخيراً با بيشرفت تكنولوزى، درخواست براى قطعات با دقت بالا كه داراى قابليت توليد زياد و اطمينان از كيفيت مناسب باشند در

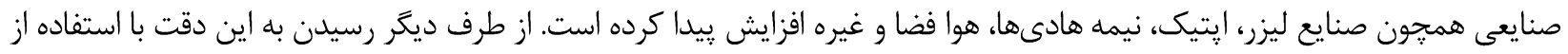

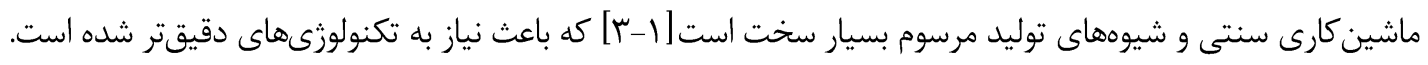

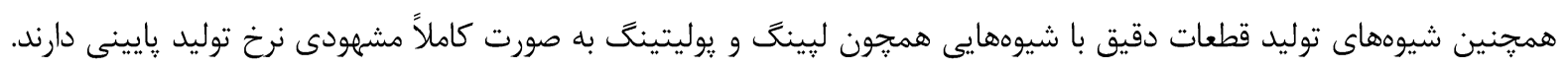

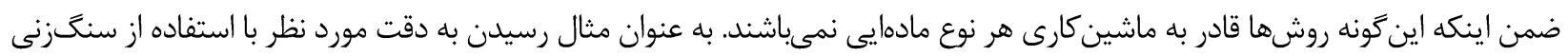

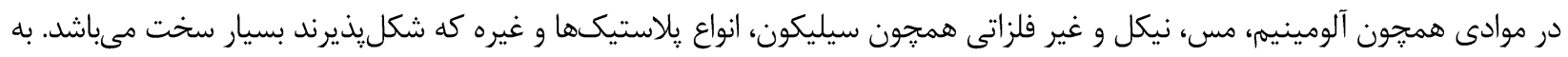

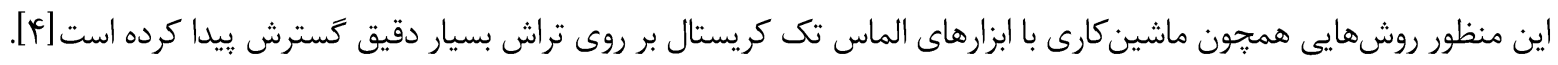


به صورت همزمان با افزايش درخواست براى قطعات با دقت بالا، درخواست براى توليد قطعات كوجى با اشكال پيجٍيده و با اندازمهاى

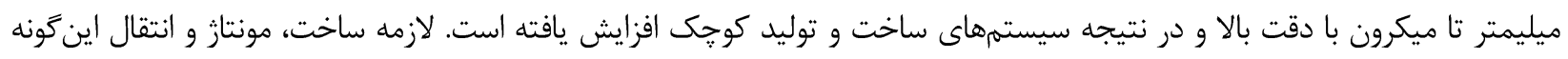

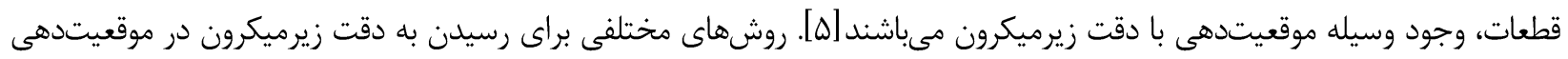

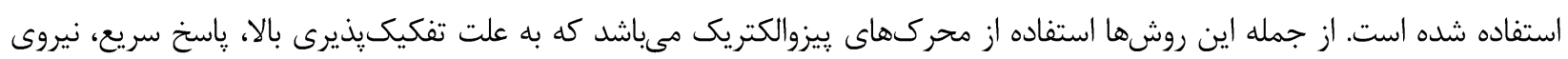
توليدى بالاو سادگى براى كوجكسازى در سطح وسيعى براى موقعيتدهى در اندازه ميكرون به كار گرفته شده است.

در سال 1999 ميكروتراشى با قابليت حركت در دو جهت توسط آزمايشكاه مهندسى مكانيك زإين براى ماشينكارى قطعات بسيار

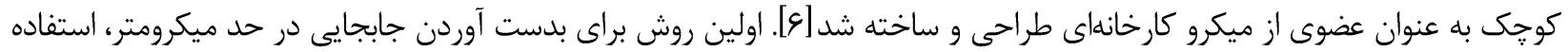

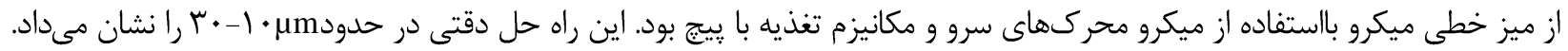

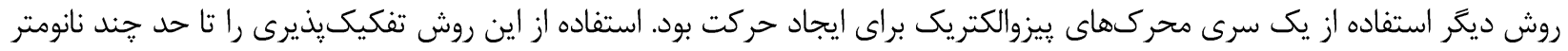

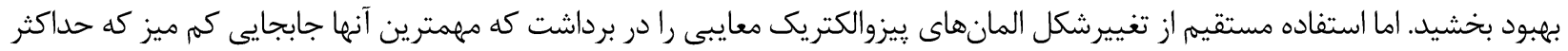

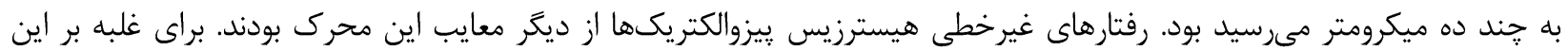

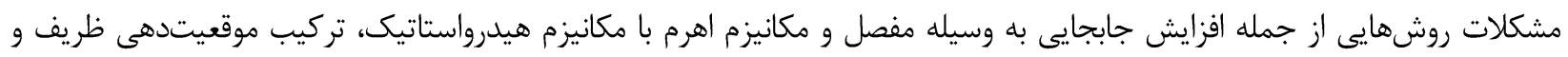

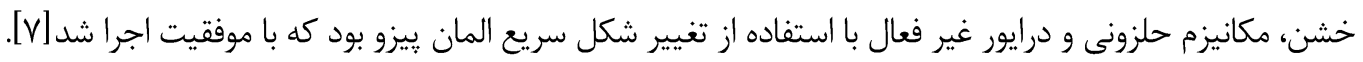
ساخت موقعيتدهندالى با استفاده از اصل حركت حلزونى و سه المان بيزوالكتريك فعال در داخل آن از مهمترين اين روشها است كه دو عد از يِيزوها براى كيرهبندى و يكى به عنوان محرك ييشروى به كار ترفته شد و تكرار گيرهبندى و ويشروى حركت مورد نظر را

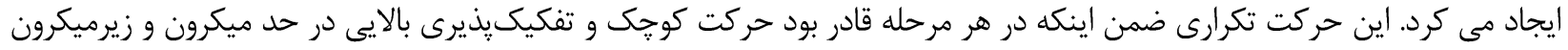

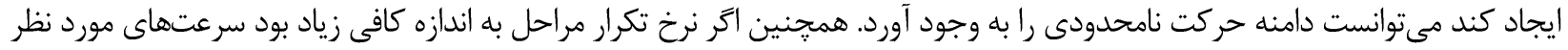

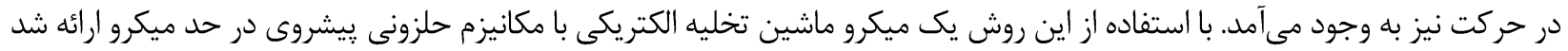

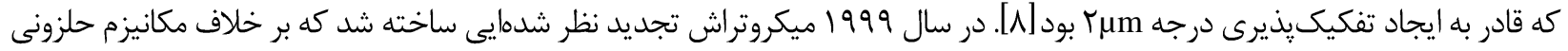

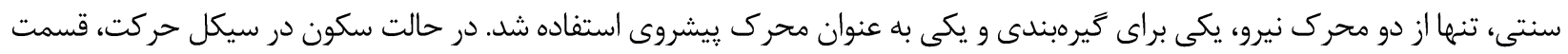

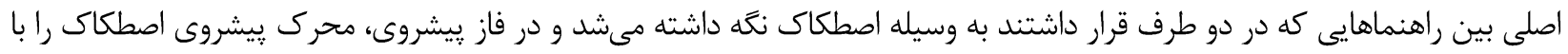

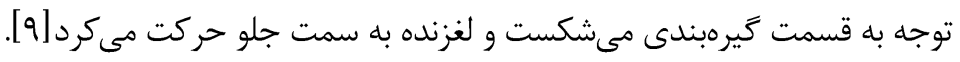
در اين مقاله موقعيتدهندهاى از نوع حلزونى به منظور استفاده در لغزندههاى ميكروتراش ارائه شده است. اين موقعيتدهنده شامل

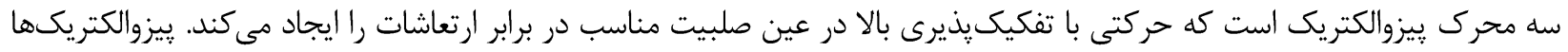
نيز به منظور ايجاد نيرو و جابجايى بيشتر از نوع لايهاى انتخاب شده است. همجنين جنس وييزوالكتريكهاى كيرهبندى و ييشروى به علت

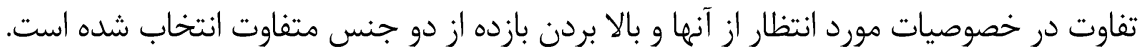

\section{r- خصوصيات ظاهرى و شيوه حر كت حلزونى}

به منظور ايجاد حركت با استفاده از اين لغزندهها بسته به اينكه لغزنده بخواهد به كدام سمت حركت كند ابتدا محرك گيرهبندى اول

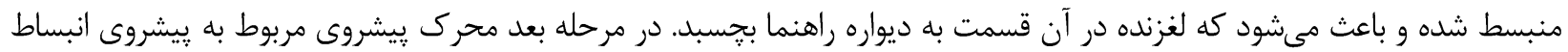




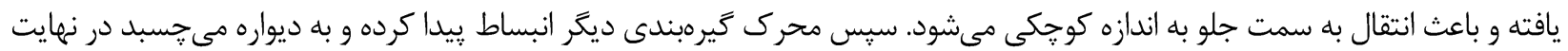

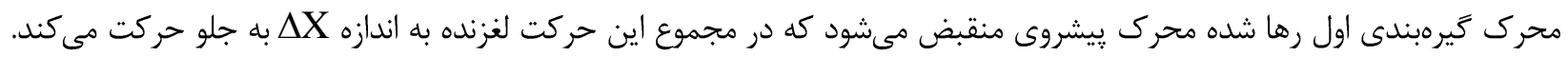

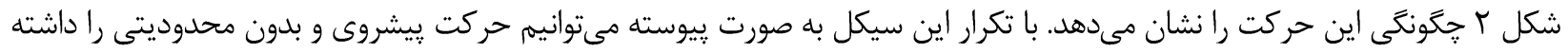

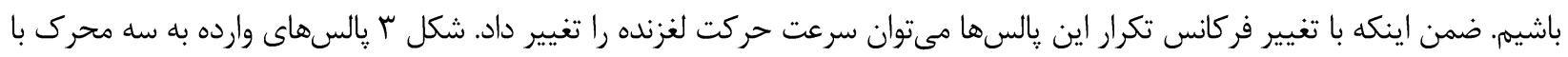

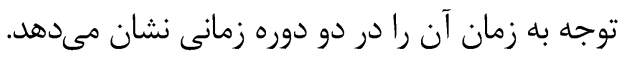
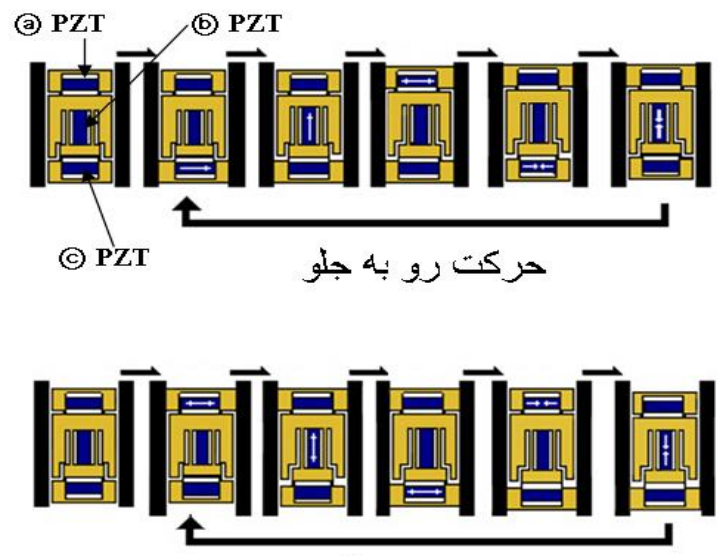

حركت رو به عقب

شكلץ - مكانيزم حركت حلزونى

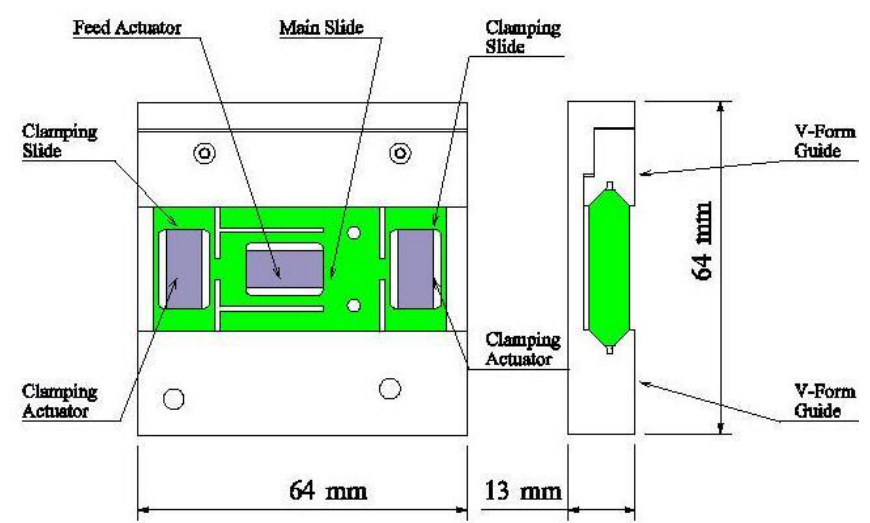

شكل ا-نماى ظاهرى لغزنده

\section{r-تحليل اجزاء محدود و شبيهسازى}

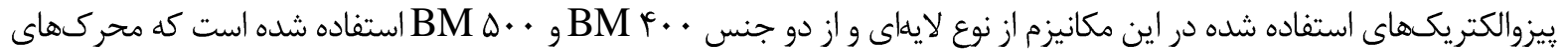

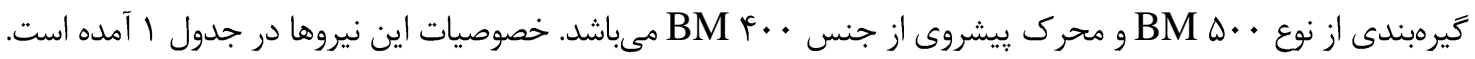

جدول 1- خصوصيات ييزو الكتريكها

\begin{tabular}{|c|c|c|c|c|}
\hline BM500 & BM400 & واحد & نماد & \\
\hline $7 \times 7 \times 15$ & $7 \times 7 \times 15$ & $\mathrm{~mm}$ & & 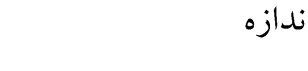 \\
\hline 1540 & 490 & $\mathrm{nF}$ & $\mathrm{C}$ & ظرفيت خازنى \\
\hline $365 e-12$ & $300 \mathrm{e}-12$ & $\mathrm{~m} / \mathrm{V}$ & $d_{33}$ & نابت بار الكتريكى \\
\hline 7650 & 7600 & $K g / m^{3}$ & $\rho$ & 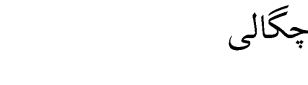 \\
\hline $19 \mathrm{e}-12$ & $15 e-12$ & $m^{2} / N$ & $s_{33}$ & تابت نرمى \\
\hline 1750 & 1350 & - & $K_{33}^{T}$ & نابت نسبى دى الكتريكك \\
\hline
\end{tabular}




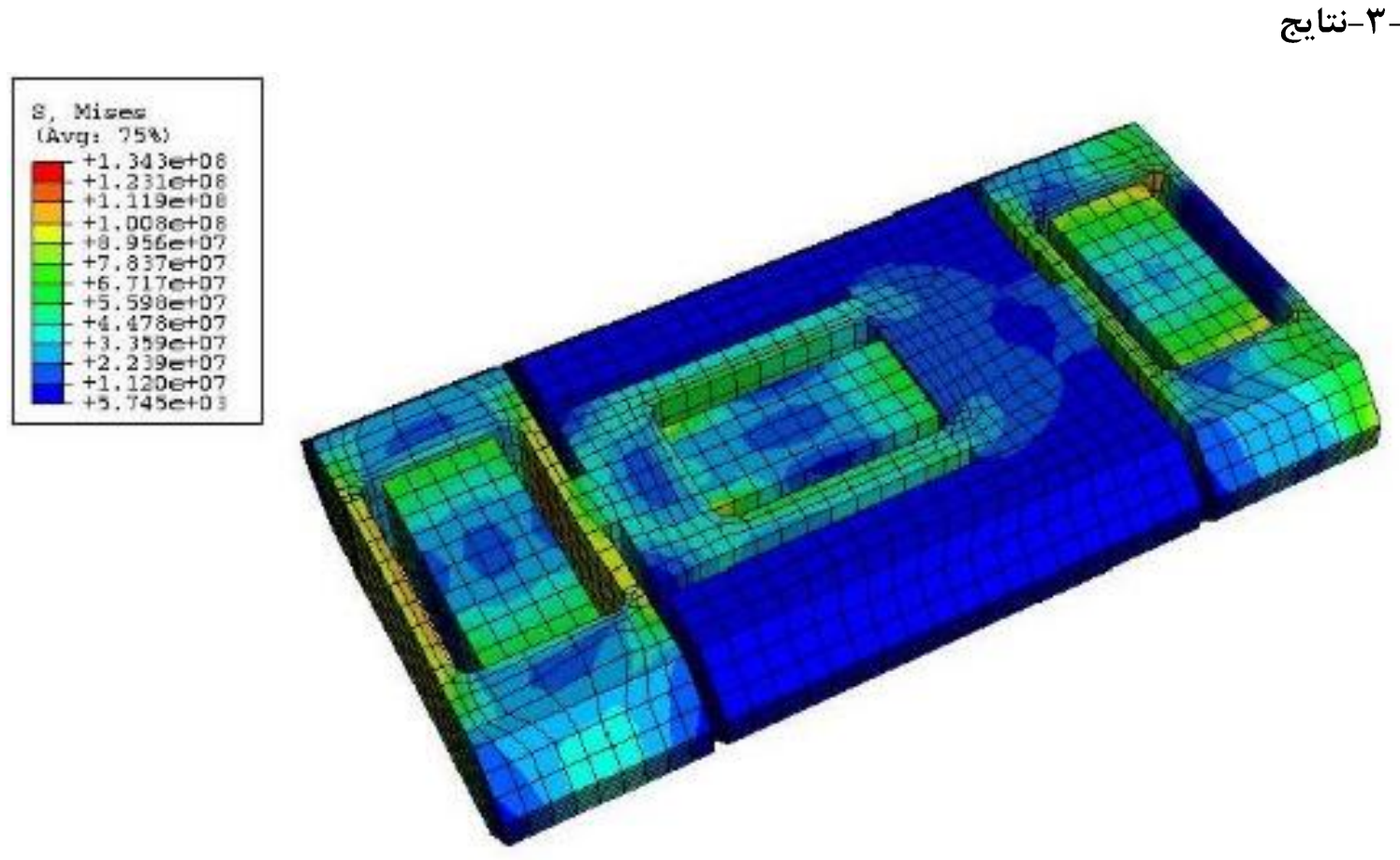

شكل r-تنش بوجود آمده در لغزنده

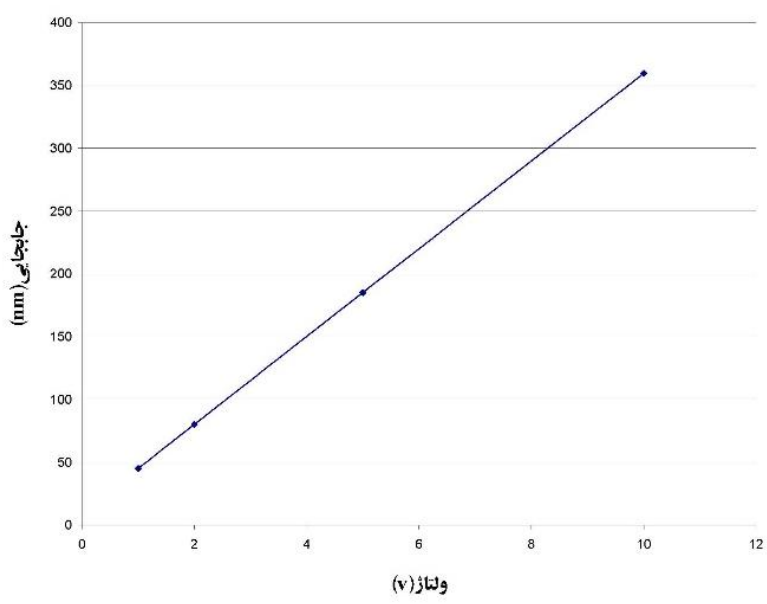

نمودار ب- نمودار جابجائى(nm) بر اساس اختلاف يتانسيل

(V) ورودى)

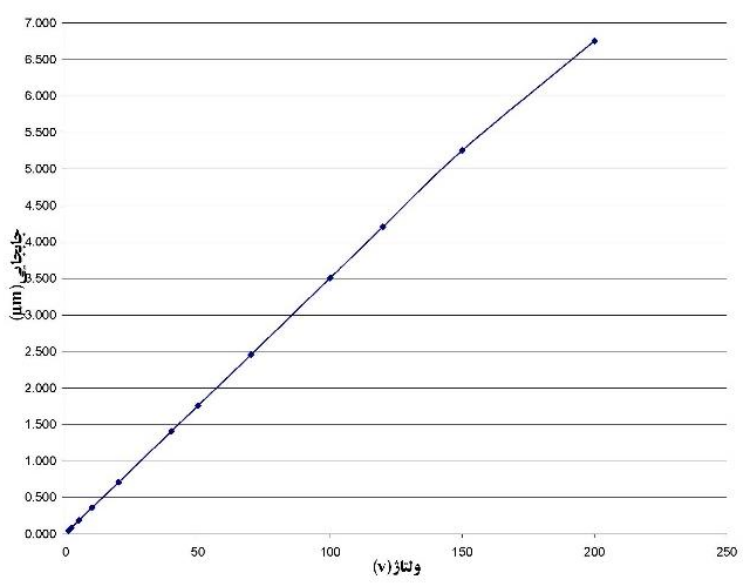

نمودار r- نمودار جابجائى (بm)بر اساس اختلاف يتانسيل

ورودى) و (V) 


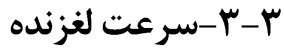

نمودار أ تأثير افزايش فر كانس بر سرعت را نشان مىدهد. با افزايش فركانس سرعت نيز به صورت خطى افزايش مىيابد. عامل ديخرى

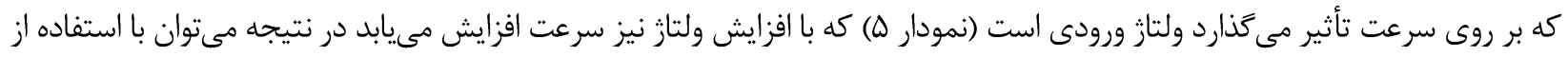

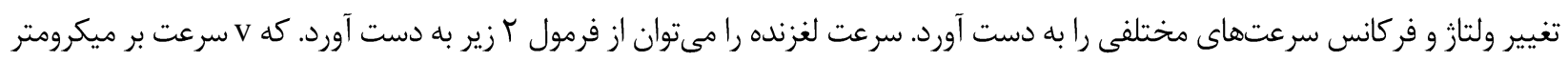

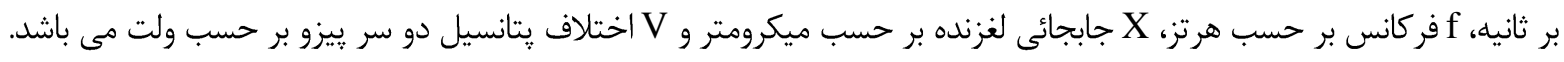

$$
\begin{aligned}
& v=X . f \\
& \Rightarrow v=(0.34 V+0.01) . f
\end{aligned}
$$

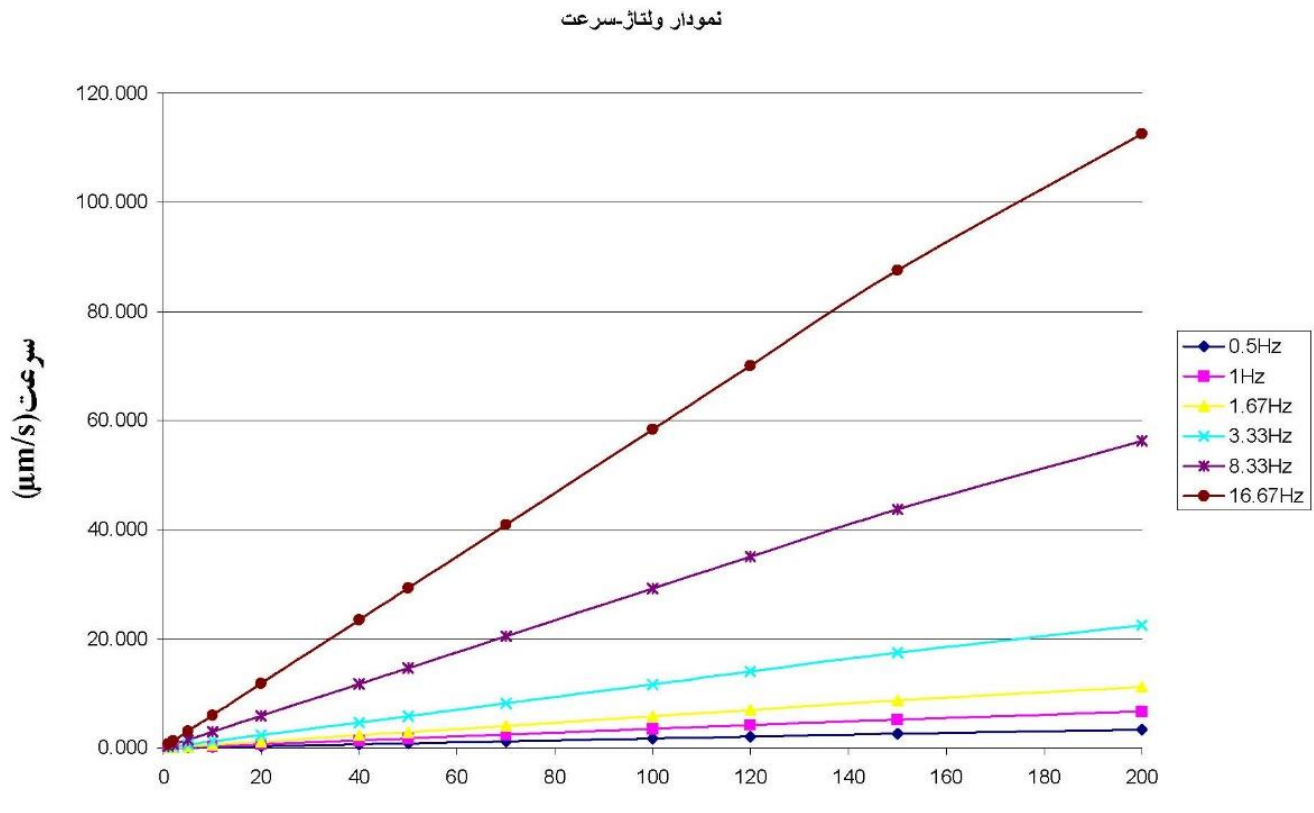

ولتاز)

نموداره - نمودار سرعت (رm/s) بر اساس اختلاف يتانسيل ورودى(V) در فر كانس هاى مختلف(Hz)

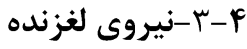

همانطور كه از فرمول ك و نمودارهاى أ و ه مشخص است براى به دست آوردن سرعت ثابتى مىتوان از مقادير متفاوتى از ولتاز و

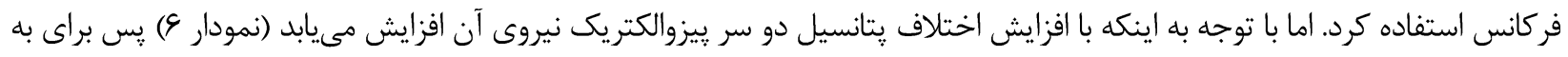

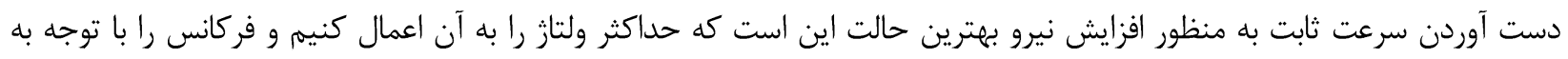

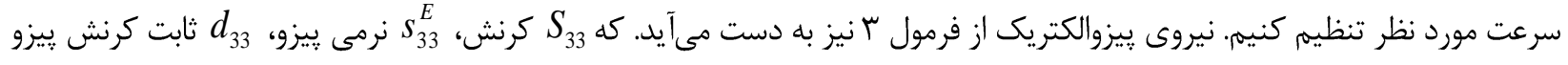

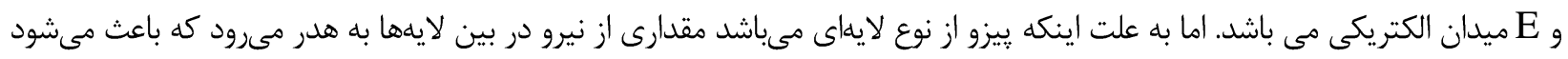

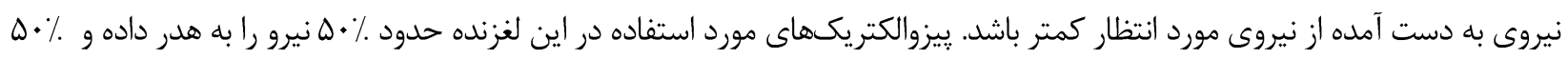
را اعمال مى كند يّ نيروى واقعى نيرو حدود نصف نيروى به دست آمده از فرمول است. 


$$
\begin{aligned}
& S_{33}=-s_{33}^{E} \frac{F}{A}+d_{33} \cdot E \\
& \square x=-s_{33}^{E} \frac{F L}{A}+d_{33} . V
\end{aligned}
$$

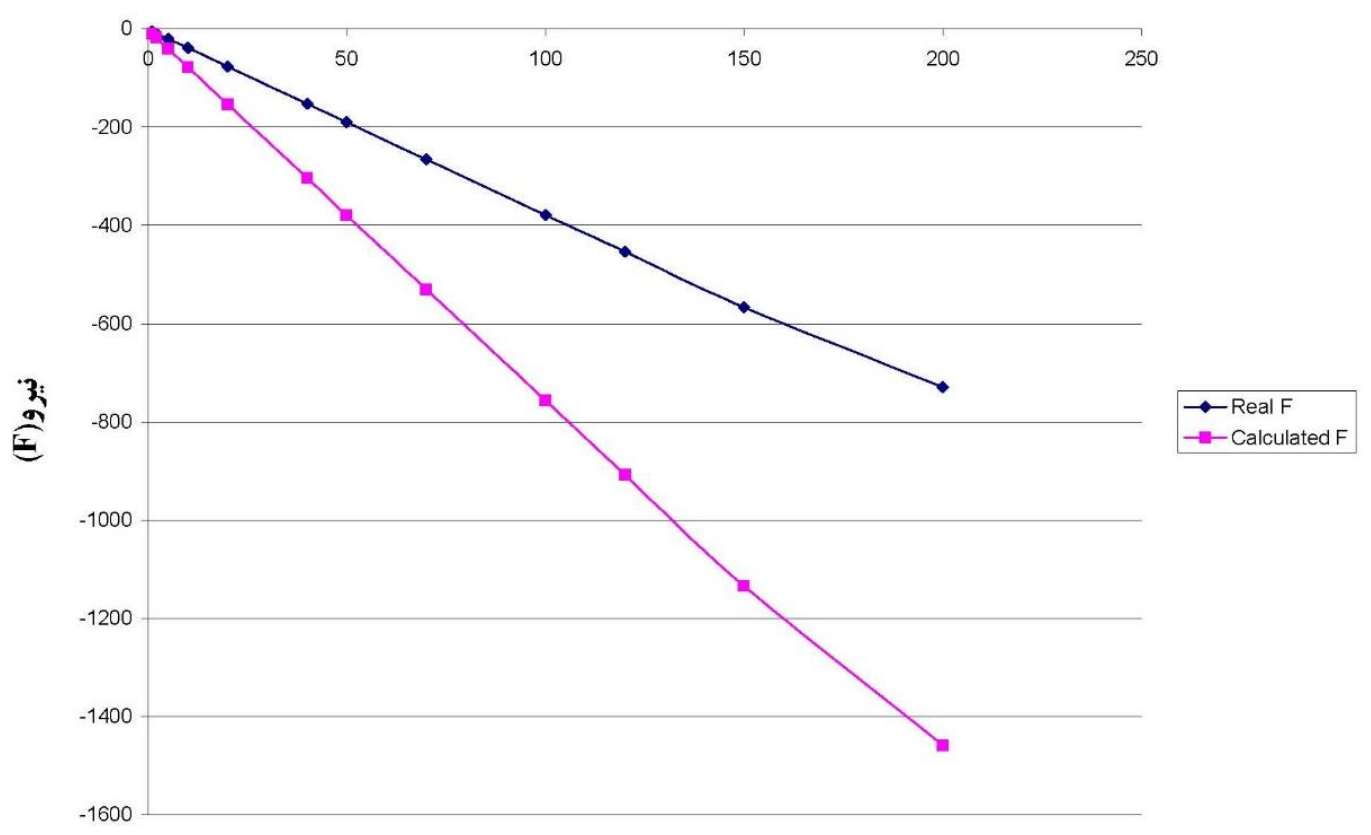

(V) اختلاف پيتانسيل

نمودار \&-نمودارنيرو (N) بر اساس اختلاف يتانسيل ورودى(V)

F

در مقاله مفهوم حركت لغزنده الى با حركت حلزونى ارائه شد. تحليل ها نشان داد كه حداكثر تفكيك بذيرى براى اين لغزنده برابر

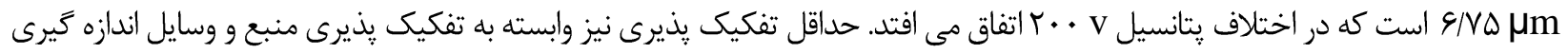

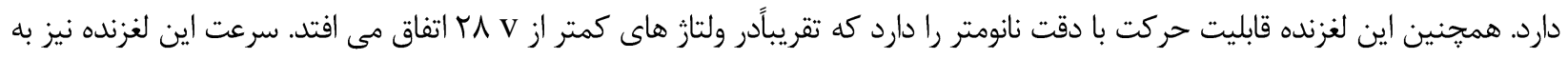

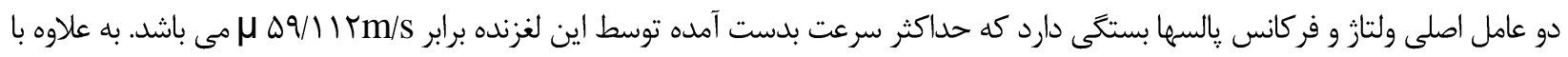

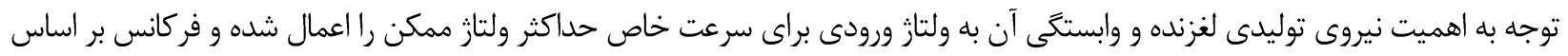
آن تنظيم مى شود.

اين لغزنده شرايط ارائه شده در ميكرو تراش، ميكرو فرز، ميكرو ماشين تخليه الكتريكى و دستكاه هايى كه در آنها نياز به دقت بالا مى

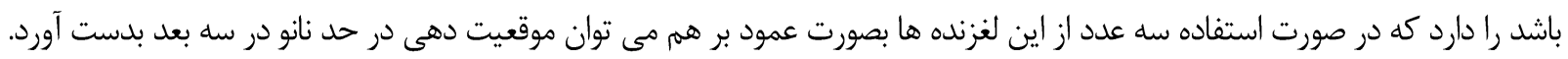



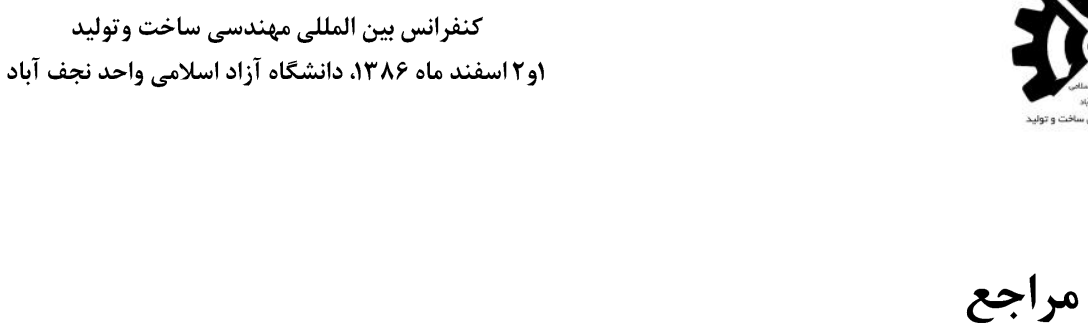

[1] Zarreh, A., 2008. Design and manufacturing evaluation of microlathe with nano positioning stage (Thesis, The University of Tehran).

[2] M. Sadeghi, A. Zarreh, M.M. Mashadi, "Design and Efficiency Evaluation of NanoPositioning System in Macro Scale with Circular Flexture Joints", 1st International Manufacturing Engineering Conference, Najaf Abad, Iran, 2008

[3] K. Ashida, N. Mishima, H. Maekawa, T. Tanikawa, K. Kaneko and M. Tanaka, "Development of desktop machining Microfactory", Proc. J-USA Symposium on Flexible Automation, pp. 175-178 (2000)

[4] Yuichi OKAZAKI, Nozomu MISHIMA and Kiwamu ASHIDA," Microfactory and Micro Machine Tools", 1st Korea-Japan Conference on Positioning Technology, Daejeon, Korea, 2002

[5] Y. Okazaki and T. Kitahara, "NC micro-lathe to machine micro-parts", Proc. 2000 ASPE Annual Meeting, pp. 575-578 (2000)

[6] Jian Li, Ramin Sedaghati, Javad Dargahi, David Waechter, "Design and development of a new piezoelectric linear Inchworm actuator", Mechatronics 15 (2005), pp 651-681

[7] Bexell M, Johansson S. "Characteristics of piezoelectric miniature motor". Sensors Actuators 1999;(75), 118-30.

[8] Stibitz GR. Incremental Feed Mechanisms. Patent \#3,138,749, 1964. 